\title{
Economic Base Multipliers Revisited
}

\author{
Derek Bond, Michael J. Harrison and
}

Edward J. O’Brien

TEP Working Paper No. 0807

June 2007

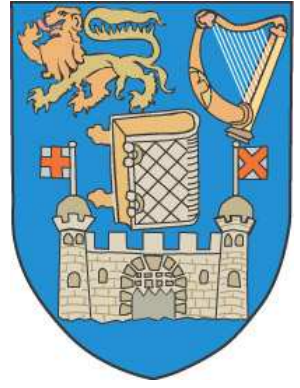

Trinity Economics Papers

Department of Economics

Trinity College Dublin 


\title{
Economic Base Multipliers Revisited
}

\author{
Derek Bond $^{a} \quad$ Michael J. Harrison ${ }^{b, *} \quad$ Edward J. O’Brien ${ }^{c}$
}

June 7, 2007

a University of Ulster, Coleraine, Co. Londonderry, BT52 1SA, UK

b University of Dublin, Trinity College, Dublin 2, Ireland

c European Central Bank, Kaiserstraße 29, D-60311 Frankfurt am Main, Germany

\begin{abstract}
This paper takes a fresh look at the estimation of economic base multipliers. It uses recent developments in both nonstationary and nonlinear inference to consider issues surrounding the derivation of such multipliers for Northern Ireland. It highlights the problem of distinguishing between nonstationarity and nonlinearity in empirical work. The results of standard unit root and cointegration analysis call into question the adequacy of that framework for estimating employment multipliers. There is strong evidence of nonlinearity; and modelling using random field regression supports the findings of Harrison and Bond (1992) that there is substantial parameter instability or nonlinearity in the data.
\end{abstract}

\section{JEL Classification: C22, C52, R12}

Keywords: Economic base multiplier; fractional Dickey-Fuller test; random field regression.

\footnotetext{
${ }^{*}$ Corresponding author. Tel.: +3531 8961946; Fax: +35316772503.

Email addresses: d.bond@ulster.ac.uk (D. Bond), mhrrison@tcd.ie (M.J. Harrison), edward.obrien@ecb.int (E.J. O'Brien).
} 


\section{INTRODUCTION}

While there are concerns about the theoretical validity of economic base multipliers (see, for example, Pfester, 1976) they provide policy makers with a simple way to estimate the impact of new policies. ${ }^{1}$ Most inference on economic base multipliers is now conducted within the cointegration framework, introduced independently by Bond (1990), LeSage (1990) and Brown, Coulson and Engle (1992). In this framework, the underlying data are viewed as being nonstationary $I(1)$ series. The long-run multipliers can be obtained from a cointegrating 'levels' model and the short-run multipliers from a dynamic error-correction model (ECM). Bond (1990) and Brown, Coulson and Engle (1992) also suggest that the economic base can be identified by maximising the likelihood of the series being cointegrated. While this approach to estimating multipliers seemed sound, concerns were soon raised. Harrison and Bond (1992) discussed the possibility of the observed dynamic behaviour being due to structural instability. Since then there have been several developments in the testing and estimation of both nonstationary and nonlinear economic models. The aim of this paper is to apply some of these developments to the estimation of economic base multipliers.

The structure of the paper is as follows. In Section 2, the work of Bond (1990), LeSage (1990), Brown, Coulson and Engle (1992) and Harrison and Bond (1992) is briefly outlined. In Section 3, two developments in econometric methodology, namely, fractional integration and random field inference, are introduced. The results of applying techniques from these areas to the original data of Bond (1990) and Harrison and Bond (1992) are discussed in Section 4. The paper concludes, in Section 5 , by discussing whether these new techniques provide a sounder method for estimating economic base multipliers than the cointegration approach employed previously.

\section{ECONOMIC BASE MULTIPLIERS AND COINTEGRATION}

In the economic base approach, the economy of a region is normally divided into three sectors: the base or export sector $(X)$ that produces output for consumption 
on a wider market; the non-base or service sector $(S)$ that is mainly concerned with servicing the local economy; and the autonomous sector $(A)$, which produces for national requirements. Let $\left\{X_{t}\right\}_{t=1}^{T},\left\{S_{t}\right\}_{t=1}^{T}$ and $\left\{A_{t}\right\}_{t=1}^{T}$ be time series of employment in these respective sectors. Considering the equation

$$
S_{t}=\alpha+\beta_{1} X_{t}+\beta_{2} A_{t}+\epsilon_{t}, \quad t=1,2, \ldots, T,
$$

where $\epsilon_{t}$ is a white noise error term, the base and autonomous long-run employment multipliers, i.e., the long-run changes in total employment that result from a unit increase (or decrease) in employment in the base and autonomous sectors, respectively, are given by $\left(1+\beta_{1}\right)$ and $\left(1+\beta_{2}\right)$. Placing the discussion in a cointegration framework, it is argued that $\left\{X_{t}\right\}_{t=1}^{T},\left\{S_{t}\right\}_{t=1}^{T}$ and $\left\{A_{t}\right\}_{t=1}^{T}$ are $I(1)$ series and that Equation (1) is a cointegrating 'levels' equation. If this is the case, the Representation Theorem (see, for example, Engle and Granger, 1987) implies that an ECM representation of Equation (1) must exist. The standard form of such a model is

$\Delta S_{t}=\alpha_{1}+\sum_{i=1}^{p} \vartheta_{i} \Delta S_{t-i}+\sum_{i=0}^{q} \varphi_{i} \Delta X_{t-i}+\sum_{i=0}^{r} \lambda_{i} \Delta A_{t-i}+\varsigma Z_{t}+\nu_{t}, \quad t=1,2, \ldots, T$, where $\Delta$ is the first difference operator, such that, for example, $\Delta X_{t}=X_{t}-X_{t-1}$, $Z_{t}$ is an error-correction term, and $\nu_{t}$ is a white noise disturbance. In many studies, $Z_{t}$ is taken to be $\hat{\epsilon}_{t-1}$, the lagged ordinary least squares residual from Equation (1).

The standard approach to estimating economic base multipliers then reduces to:

- Allocating employment to either base, autonomous or service sectors.

- Testing the order of integration of the series.

- Estimating the levels models.

- Estimating the ECM, using a general-to-specific modelling strategy.

- Re-allocating employment and repeating the procedure until the optimal cointegrating relationship is found.

The simplicity of the approach is appealing but hides many problems for the unwary. Unit root tests such as the augmented Dickey-Fuller (1979) (ADF) test 
are known to have low power. Only with the work of MacKinnon (1996) did reliable figures for the critical values and asymptotic $p$-values for these tests become available. There is growing disquiet about the 'knife-edge' nature of the $I(0) / I(1)$ dichotomy; see, for example, Maynard and Phillips (2001). Perron (1989) and others raised the problem that it is difficult to distinguish between stationary series with structural breaks and nonstationary series. Some of these points were taken up in Harrison and Bond (1992), where various tests for structural breaks, including that of Bai, Lumsdaine and Stock (1998), and Kalman filtering were used to investigate the structural stability of the models used in Bond (1990). In recent years, two approaches to econometric modelling have been developed that may help to address some of these issues. In the area of nonstationarity, more powerful unit root tests have been developed, as well as the methodology for handling fractionally integrated series, including the introduction of a simple fractional ADF (FADF) test. In the area of nonlinear inference, there have been developments both in testing for structural breaks and in more general inference, using the concept of random fields. This paper concentrates on the use of the FADF and random field regression approaches to explore the characteristics of economic base multipliers.

\section{FRACTIONAL INTEGRATION AND RANDOM FIELDS}

In this section, the parametric test for fractional integration introduced by Dolado, Gonzalo and Mayoral (2002), and the random field (RF) approach to nonlinearity proposed by Hamilton (2001), are briefly described. Both will be used in the following section to explore the validity of the standard cointegration approach to estimating economic base multipliers.

\section{Fractional Integration}

A series $\left\{y_{t}\right\}_{t=0}^{\infty}$ is said to be integrated to order $d$, denoted by $I(d)$, if the series must be differenced $d$ times before it is at least asymptotically stationary. In the classical approach, $d$ is an integer, usually unity, and the majority of empirical economic investigations have involved this $I(1) / I(0)$ framework. That is, either $\Delta y_{t}=y_{t}-y_{t-1}$ or $y_{t}$, is taken to be (asymptotically) stationary. By allowing for 
fractional integration, the restriction that $d$ is an integer is relaxed. This leads to a more general formula for an integrated series of order $d$, given by

$$
\Delta^{d} y_{t}=y_{t}-d y_{t-1}+\frac{1}{2 !} d(d-1) y_{t-2}-\ldots+\frac{(-1)^{j}}{j !} d(d-1) \ldots(d-j+1) y_{t-j}+\ldots
$$

In the case where $0<d<1$, it follows that not only the immediate past value of $y_{t}$, but values from previous time periods influence the current value. If $0<d<0.5$, then the series $\left\{y_{t}\right\}_{t=0}^{\infty}$ is stationary; and if $0.5 \leq d<1.0$, then $\left\{y_{t}\right\}_{t=0}^{\infty}$ is nonstationary.

\section{The Fractional Augmented Dickey-Fuller Test}

Dolado, Gonzalo and Mayoral (2002) proposed a test for fractional integration that is, perhaps, simpler to apply than the LM test used by Robinson (1994), and in the case where a consistent estimate of $d$ is used, whose test statistic follows a standard normal distribution. The test can be viewed as a fractional version of the augmented Dickey-Fuller test, and involves estimating the equation

$$
\Delta y_{t}=\theta \Delta^{d} y_{t-1}+\sum_{i=1}^{p} \Delta y_{t-i}+\epsilon_{t} .
$$

The test of the null hypothesis $H_{0}: \theta=0$ is a test of the hypothesis that $d=1$ against the alternative that $0<d<1$.

Various consistent estimators of $d$ are available. Using an 'over-differenced' ARFIMA model, i.e., using $\Delta y_{t}$ rather than $y_{t}$, two parametric estimates of $d$ can be obtained using the Doornik and Ooms (1999) ARFIMA package. The first is the exact maximum likelihood (EML) estimator, which uses the algorithm suggested by Sowell (1992). This approach requires that $d<0.5$, which together with the problem of drift is another reason for using the 'over-differenced' model; see, for example, Smith, Sowell and Zin (1997). The second is an approximate maximum likelihood estimator based on the conditional sum of squared naïve residuals, developed by Beran (1995) and called by Doornik and Ooms (1999) a nonlinear least squares (NLS) estimator. Two standard semiparametric estimators are also available in the same package: the log-periodogram regression method introduced by Geweke and Porter-Hudak (1983) 
(GPH), and the semiparametric Whittle estimator of Robinson (1995) (GSP). These semiparametric estimators of $d$ have the advantage that they are robust against the misspecification of the short-run dynamics of the process, unlike the parametric estimators. However, they can be sensitive to the specification of the frequency.

\section{Investigating Nonlinearity Using The Random Field Approach}

Diebold and Inoue (2001), building on the work of Perron (1989), highlighted the problems of distinguishing between the possibilities that a series is fractionally integrated or nonlinear. A general approach to investigating nonlinearity in economic relationships is random field regression, introduced by Hamilton (2001). Dahl (2002) showed that the random field approach has relatively better small sample fitting abilities than a wide range of parametric and nonparametric alternatives, including the logistic (LSTR) and exponential (ESTR) models commonly used in modelling nonlinearity as a smooth transition autoregressive process.

If $y_{t}$ is stationary, $\epsilon_{t}$ is a $N I D\left(0, \sigma^{2}\right)$ error and $\mathbf{x}_{t}$ is a $k$-vector of explanatory variables that may include lagged dependent variables, then the basic regression model is of the form

$$
y_{t}=\mu\left(\mathbf{x}_{t}\right)+\epsilon_{t},
$$

where the functional form $\mu\left(\mathbf{x}_{t}\right)$ is unknown and assumed to be the outcome of a random field. Hamilton (2001) argues for representing the conditional mean function, $\mu\left(\mathbf{x}_{t}\right)$, as consisting of two components. The first is the usual linear component, while the second, a nonlinear component, is treated as stochastic and hence unobservable. Both the linear and nonlinear components contain unknown parameters that need to be estimated. Following Hamilton, the conditional mean function can written as

$$
\mu\left(\mathbf{x}_{t}\right)=\alpha_{0}+\boldsymbol{\alpha}^{\prime} \mathbf{x}_{t}+\lambda m\left(\overline{\mathbf{x}}_{t}\right),
$$

where $\overline{\mathbf{x}}_{t}=\boldsymbol{g} \odot \mathbf{x}_{t}, \boldsymbol{g}$ is a $k$-vector of parameters and $\odot$ denotes the Hadamard product of matrices. The function $m\left(\overline{\mathbf{x}}_{t}\right)$ is referred to as the random field. If the random field is Gaussian, it is defined fully by its first two moments. If $\boldsymbol{H}_{k}$ is the covariance matrix of the random field, with a typical element $H_{k}(\mathbf{x}, \mathbf{z})=$ 
$E[m(\mathbf{x}) m(\mathbf{z})]$, Equation (2) can be rewritten as

$$
y_{t}=\alpha_{0}+\boldsymbol{\alpha}^{\prime} \mathbf{x}_{t}+u_{t}
$$

where $u_{t}=\lambda m\left(\overline{\mathbf{x}}_{t}\right)+\epsilon_{t}$, or in matrix form

$$
\mathbf{y}=\mathbf{X} \boldsymbol{\beta}+\mathbf{u}
$$

where $\boldsymbol{\beta}=\left[\alpha_{0} \boldsymbol{\alpha}^{\prime}\right]^{\prime}$. It follows, therefore, that

$$
\mathbf{u} \sim N\left(\mathbf{0}, \lambda^{2} \boldsymbol{H}_{k}+\sigma^{2} \boldsymbol{I}_{T}\right)
$$

By treating equations (4) and (5) as a generalised least squares problem, the profile maximum likelihood function associated with the problem can be obtained and maximised with respect to the various parameters of interest. The only difficulty is that the form of the covariance matrix is unknown. Hamilton derives $\boldsymbol{H}_{k}$ as a simple moving average representation of the random field, based on $\boldsymbol{g}$ using an $L_{2}$-norm measure. He shows that even under fairly general misspecification, it is possible to obtain consistent estimators of the conditional mean. Additional results on the consistency of the parametric estimators obtained from this approach are given in Dahl, González-Rivera and Qin (2005).

\section{Testing For Nonlinearity Using Random Fields}

The use of random field models provides an attractive way of estimating and testing for nonlinear economic and financial relationships. The additive random field function used by Hamilton (2001) suggests that a simple method of testing for nonlinearity is to check if $\lambda$, or $\lambda^{2}$, is zero or not. Hamilton showed that if $\lambda^{2}=0$, and the nonlinear model is estimated for a fixed $\boldsymbol{g}$, the maximum likelihood estimate $\widetilde{\lambda}^{2}$ is consistent and asymptotically normal. Thus a test based on the use of the standard normal distribution is possible, though computationally complex. Given the assumption of normality and the linearity of Equation (2), under the null hypothesis that $\lambda^{2}=0$, a simpler alternative uses the Lagrange multiplier principle. Hamilton 
showed that provided the covariance function of the random field can be derived, for a fixed $\boldsymbol{g}$ (Hamilton uses the mean of its prior distribution) this only requires a single linear regression to be estimated. Hamilton derived the appropriate score vectors of first derivatives, for up to $k=5$, along with the associated information matrix, and proposed a form of the LM test for practical application. As $\lambda_{H}^{E}(\boldsymbol{g})$, the test statistic, ${ }^{2}$ is distributed as $\chi_{1}^{2}$ under the null hypothesis, linearity would be rejected if $\lambda_{H}^{E}(\boldsymbol{g})$ exceeded the critical value $\chi_{1, \alpha}^{2}$, for the chosen level of significance, $\alpha$. For example, at the $\alpha=5$ per cent level, the null hypothesis would be rejected if $\lambda_{H}^{E}(\boldsymbol{g})>3.84$.

The usefulness of the Hamilton LM test depends on a set of nuisance parameters that are only identified under the alternative hypothesis. As Hansen (1996) shows, dealing with unidentified nuisance parameters by assuming full knowledge of the parameterised stochastic process that determines the random field may have adverse effects on the power of the test. To take account of this, Dahl and González-Rivera (2003) introduced a series of LM tests that extends the Hamilton approach. The first, the $\lambda_{O P}^{E}(\boldsymbol{g})$ test, like Hamilton's approach, assumes knowledge of the covariance matrix, but its behaviour is based on the $L_{1}$-norm. The nuisance parameters are still

present, but in this case only enter the test in a linear fashion. The second, the $\lambda_{O P}^{A}$ test, only assumes that the covariance function is smooth enough to be approximated by a Taylor expansion. The final approach is a test of the null hypothesis $H_{0}: \boldsymbol{g}=\mathbf{0}$ called the $g_{O P}$ test, which makes no assumption about either the covariance function or $\lambda$. Dahl and González-Rivera (2003) show that the $\lambda_{O P}^{A}$ and $g_{O P}$ tests have, in many circumstances, better power than other tests of nonlinearity. ${ }^{3}$

\section{Estimating Random Field Models}

The full power of Hamilton's (2001) random field approach is only realised when the parameters $\lambda$ and $\boldsymbol{g}$ are estimated. In particular, the estimated value of $\boldsymbol{g}$ can be used for inference on the form of the nonlinearity. A highly significant $g_{i}$, where $i=$ $1, \ldots, k$, suggests that the corresponding explanatory variable plays an important role in the nonlinearity of the model. Hamilton showed that estimating the unknown parameters, $\boldsymbol{\varphi}=\left\{\alpha_{0}, \boldsymbol{\alpha}, \boldsymbol{g}, \sigma^{2}, \lambda\right\}$, can be reduced to maximum likelihood estimation 
of a reparameterisation of equations (2) and (3):

$$
\begin{gathered}
\eta(\mathbf{y}, \mathbf{X} ; \boldsymbol{g}, \zeta)=-\frac{T}{2} \ln (2 \pi)-\frac{T}{2} \ln \sigma^{2}(\boldsymbol{g}, \zeta)-\frac{1}{2} \ln |\mathbf{W}(\mathbf{X} ; \boldsymbol{g}, \zeta)|-\frac{T}{2}, \\
\tilde{\boldsymbol{\beta}}(\boldsymbol{g}, \zeta)=\left[\mathbf{X}^{\prime} \mathbf{W}(\mathbf{X} ; \boldsymbol{g}, \zeta)^{-1} \mathbf{X}\right]^{-1}\left[\mathbf{X}^{\prime} \mathbf{W}(\mathbf{X} ; \boldsymbol{g}, \zeta)^{-1} \mathbf{y}\right], \\
\tilde{\sigma}^{2}(\boldsymbol{g}, \zeta)=\frac{1}{T}[\mathbf{y}-\mathbf{X} \tilde{\boldsymbol{\beta}}(\boldsymbol{g} ; \zeta)]^{\prime} \mathbf{W}(\mathbf{X} ; \boldsymbol{g}, \zeta)^{-1}[\mathbf{y}-\mathbf{X} \tilde{\boldsymbol{\beta}}(\boldsymbol{g} ; \zeta)],
\end{gathered}
$$

where $\zeta=\lambda / \sigma$ and $\mathbf{W}(\mathbf{X} ; \boldsymbol{g}, \zeta)=\zeta^{2} \boldsymbol{H}_{k}+\boldsymbol{I}_{T}$. The profile likelihood can be maximised with respect to $(\boldsymbol{g}, \zeta)$, using standard maximisation algorithms. Once estimates for $\boldsymbol{g}$ and $\zeta$ have been obtained, equations (6) and (7) can be used to obtain estimates of $\boldsymbol{\beta}$ and $\sigma$. As Bond, Harrison and O'Brien (2005) point out, however, care needs to be taken when maximising the likelihood due to computational issues. Also, as Hamilton (2005) explains, it is possible for the nonlinearity tests based on $\lambda$ to be highly significant, but the results of the nonlinear optimisation of the likelihood function to suggest that $\zeta$ is insignificant. This may relate to what, in the time series literature, is known as the "pile-up" phenomenon associated with numerical optimisation. This may signal that the covariance structure used for the random field, if not the normality assumption itself, may not be entirely appropriate; see DeJong and Whiteman (1993) and Hamilton (2005).

\section{METHODOLOGY AND RESULTS}

To investigate the usefulness of both Dolado, Gonzalo and Mayoral's (2002) FADF test and the random field based nonlinearity tests in helping to explore economic base multipliers, the data and models discussed in Bond (1990) were used. The data relate to quarterly employment estimates for Northern Ireland for two time periods: June 1959 to June 1971 and June 1978 to December 1986. Two groupings of employment at Standard Industrial Classification (SIC) level were considered. In the first, Model 1, the construction SIC was placed in the autonomous sector; in the second, Model 2, construction was placed in the non-base sector. The base sector is the same for both models.

To begin, the standard $I(1) / I(0)$ analysis using the ADF was conducted using the 
strategy of Dolado, Jenkinson and Sosvilla-Rivero (1990), to determine whether the series are trend stationary or difference stationary. The lag length for the ADF test was determined using the modified Akaike information criterion (MAIC), which Ng and Perron (2001) showed to be a generally better decision criterion than others, as it takes account of the persistence found in many series. The Kwiatkowski, Phillips, Schmidt and Shin (1992) (KPSS) and Ng and Perron (2001) (NP) tests were also applied. The latter is generally more powerful against the alternative of fractional integration than the standard ADF test (Perron and Ng, 1996). The FADF test of Dolado, Gonzalo and Mayoral (2002) is then employed, using four estimators of the differencing parameter $d$, namely, EML, NLS, GPH and GSP, provided by the Ox package ARFIMA (Doornik and Ooms, 1999). The MAIC is again used to determine the lag length in the FADF test equation. The RF tests for nonlinearity are then applied to the various specifications of the model, the Gauss code provided at http://weber.ucsd.edu/ jhamilto/ being used for this. To investigate further the possible causes of any nonlinearity, the random field model is estimated by maximising the profile likelihood function.

The results of preliminary unit root tests are given in Table 1, which along with all other tables, can be found in the Appendix. The ADF test results vary from those presented in Bond (1990) and Harrison and Bond (1992), as the MAIC criteria for determining lag lengths, the testing procedure of Dolado, Jenkinson and SosvillaRivero (1990), together with the probabilities derived by MacKinnon (1996), were used. For all series, there was no evidence of a trend, and only for two series in the latter period, Base and Autonomous in Model 2, was there any evidence of a constant term in the ADF regression. The results presented in Table 1 are less clear than those given in Bond (1990). The ADF tests suggest that all series are $I(1)$, with the exception of the two series which included a constant in the DickeyFuller regression; these were both found to be $I(0)$. The KPSS test, which has a null hypothesis of stationarity, only rejects the null for four series, including the two series which the ADF suggests might not be $I(1)$. The NP test, which has a null of $I(1)$, does not reject the null for any series. It is noteworthy that the KPSS test does not reject the null of stationarity in six cases in which the other two tests do not 
reject the unit root null.

Table 2 contains the results of the fractional integration analysis. In many cases the estimate of $d$ was 1 or more, precluding the use of the FADF test. The table would seem to suggest that most series are not fractionally integrated. In the first time period, 1959-1971, only the two Autonomous series seem likely to be fractionally integrated, though the conclusion is complicated by the existence of estimates of $d$ for the series of 1 or more. For the second time period, 1978-1986, only the Nonbase series in Model 1, and the Autonomous series in Model 2, appear likely to be fractionally integrated. Again, inference is complicated by the differing values of $d$.

The results of the standard 'levels' regression models are given in Table 3. The estimates are similar to those obtained in Harrison and Bond (1992). The results of this $I(1) / I(0)$ analysis are different, however, given the findings of the unit root analysis discussed above. Using the Dolado, Jenkinson and Sosvilla-Rivero (1990) methodology, and the more precise MacKinnon (1996) probabilities, the ADF tests suggest that Model 1 is the most likely to be a cointegrating regression for both time periods. However, for all models, in both time periods, the NP test suggests that there is no cointegration, while the KPSS test suggests that there is.

Table 4 presents the results of the various random field based tests for nonlinearity. For the first time period, 1959-1972, the tests nearly always reject the null hypothesis of linearity. The $g_{O P}$ test is the only test that fails to reject the null hypothesis of linearity for Model 1, both with and without a trend. For the later time period, 1978-1986, the results are more confusing. For all models, at least one of the tests fails to reject the null hypothesis of linearity. In three of the models, the $g_{O P}$ test strongly fails to reject the null. In the one model where the $g_{O P}$ test rejects the null hypothesis, the $\lambda_{H}^{E}(\boldsymbol{g})$ test strongly fails to reject it. For Model 1 without a trend and Model 2 with a trend, two tests fail to reject the null hypothesis. Both the $\lambda_{H}^{E}(\boldsymbol{g})$ and $\lambda_{O P}^{A}$ tests, however, reject the null of linearity in every case, when bootstrapped $p$-values are used for the $\lambda_{O P}^{A}$ test, at the 5 per cent level of significance. This is noteworthy, given the findings of Harrison and O'Brien (2007), referred to in endnote 3.

Finally, Table 5 gives the results of trying to fit Hamilton's (2001) random field 
regression model to the data. These results were obtained using various algorithms and various initial parameter values for the numerical optimisation of the likelihood function. The estimates presented are those that globally maximised the likelihood function for the particular model; see Bond, Harrison and O'Brien (2005) and Hamilton (2005) for a discussion of the issues surrounding the estimation of random field models. The results are interesting and need careful interpretation. The most obvious result is that in the second period, it proved impossible to get the numerical optimisation algorithms to converge for Model 1 when no trend was present, and for Model 2 when a trend was present. It is for these two models that the tests for nonlinearity, reported in Table 4, often fail to reject the null hypothesis of linearity. Also, from Table 3, it is the no-trend version of Model 1 that is more likely to be a cointegrating relationship, according to the results of the ADF test. The two models that have been estimated for the latter period suggest that either the nonlinearity in Model 2 without a trend is due mainly to the Base series, or to a time trend in Model 1, if this is included. In both cases, however, the size of the standard error for $\zeta$ would throw doubt on the existence of a nonlinear relationship. The problem of pile-up, introduced previously, should be borne in mind in such cases. For the earlier period, 1959-1972, the results strongly support the arguments put forward in Harrison and Bond (1992) for nonlinearity in the relationships. The results for both models without a trend would suggest that the main cause of the nonlinearity is the Autonomous series; and it is noteworthy that in several cases the estimated parameters in the linear component of the random field regression are similar to the corresponding estimates from the 'levels' models given in Table 3. When a trend is included, this becomes the main source of nonlinearity for both models. However, for Model 2 when a trend is included, the size of the standard error for $\zeta$ again raises questions about the existence of a nonlinear relationship, although once again, this result may be attributable to the pile-up phenomenon. Finally, and perhaps importantly, for all models where a trend is included, the standard errors for all occurrences of the Base and Autonomous variables would suggest that these have little statistical impact on the models. This may suggest that the best way to explain the Non-base series is by a simple univariate representation. 


\section{CONCLUSION}

This paper has re-examined the issue of estimating regional employment multipliers using recent developments in econometric methodology concerning fractional integration and random field regression. The theoretical background to employment multipliers has been outlined, as has the particular approach to fractionality offered by the fractional augmented Dickey-Fuller test of Dolado, Gonzalo and Mayoral (2002) and the approach to nonlinear inference suggested by Hamilton (2001). The findings reported have highlighted the potential difficulties of placing the study of employment multipliers in the $I(1) / I(0)$ econometric framework, the approach suggested by Bond (1990), LeSage (1990), and Brown, Coulson and Engle (1992), and widely adopted thereafter.

These difficulties might relate to the low power of unit root tests, i.e., the series Base, Autonomous and Non-base may not be $I(1)$, despite indications to the contrary from unit root tests. A 'levels' regression model will not therefore represent a cointegrating relationship, but rather a 'spurious' regression. ADF tests, implemented using the procedure of Dolado, Jenkinson and Sosvilla-Rivero (1990) and the MAIC selection criterion, appear to suggest unit roots for most variables. The KPSS test offers contradictory results in many cases, while the NP test, however, generally confirms the findings of the ADF test.

While we suggested that these difficulties might also relate to fractional integration of the processes generating the series used, our results show that, in the cases examined, this possibility is unlikely and that difficulties can not be overcome solely by moving to a fractional integration framework.

Proceeding on the assumption that all variables are $I(1)$, the Engle-Granger two-step procedure offers limited support for cointegration when the ADF test is employed. By contrast, there is no support for cointegration whatsoever when the NP test is used, yet full support for cointegration when the KPSS test is used. This result appears to call into question the appropriateness of the cointegration framework for investigating employment multipliers. This finding is tentative, of course, and should be tempered by the fact that it is based on just one dataset. Further investigations need to be undertaken in this area. 
Another possibility is that the processes in question may be stationary but parametrically unstable or nonlinear. As is well known, in such a situation, standard unit root tests are not likely to reject the null hypothesis of a unit root and cointegration analysis may be adopted mistakenly. Our results provide strong evidence of nonlinearity in the data. Of the tests employed here, those found to be most powerful by Harrison and O'Brien (2007) reject the null of linearity in every case, at the 5 per cent significance level.

When the nonlinearity is modelled using a random field regression, the results remain puzzling. Although the failure of the numerical optimisation in some cases is troubling, it is unsurprising as similar failures have been documented previously (Bond, Harrison and O'Brien, 2005; Hamilton, 2005). The results for the two models and time periods differ substantially. For the earlier sample, the series Autonomous is found to be nonlinearly significant. For the later period, however, it is the Base series that is found to be significant. If a time trend is included in the specification, both Autonomous and Base are nonlinearly insignificant, and sometimes linearly insignificant, but the time trend is highly significant for both models and sample periods. This strongly suggests that there is parameter instability or nonlinearity in the data examined, in support of the findings of Harrison and Bond (1992). 


\section{Notes}

${ }^{1}$ A good starting point for recent discussions on economic base multipliers is Dietzenbacher $(2005)$.

${ }^{2}$ The notation used here is that of Dahl and González-Rivera (2003). The superscript $E$ indicates that full knowledge of the parametric nature of the covariance function is assumed. The alternative, denoted by superscript $A$, makes no specific assumption about the covariance function. The subscript $H$ shows that the Hessian is used for the information matrix. The alternative subscript $O P$ indicates that the outer product of the score function is used for the information matrix.

${ }^{3}$ Interestingly, in a forthcoming paper, Harrison and O'Brien (2007) find that the $\lambda_{O P}^{A}$ test is the most powerful of the three tests proposed by Dahl and González-Rivera (2003), for a range of data and model specifications. Its power was found to be comparable to the $\lambda_{H}^{E}(\boldsymbol{g})$ test. They also suggest that the $g_{O P}$ test performs badly in small samples, and that the asymptotic $p$-values of the test in this case are particularly unreliable. 


\section{REFERENCES}

Bai, Jushan, Robin L. Lumsdaine and James H. Stock. 1998. "Testing For and Dating Common Breaks in Multivariate Time Series," Review Of Economic Studies, 65, $395-432$.

Beran, Jan. 1995. "Maximum Likelihood Estimation of the Differencing Parameter For Invertible Short and Long Memory Autoregressive Integrated Moving Average Models," Journal of Royal Statistical Society, Series B, 57, 659-672.

Bond, Derek. 1990. "Dynamic Regional Multipliers and the Economic Base: An Application of Applied Econometric Techniques," Papers of the Regional Science Association, 69, 21-30.

Bond, Derek, Michael J. Harrison and Edward J. O'Brien. 2005. "Investigating Nonlinearity: A Note on the Estimation of Hamilton's Random Field Regression Model," Studies in Nonlinear Dynamics and Econometrics, 9, Article 2.

Brown, Scott J., N. Edward Coulson and Robert F. Engle. 1992. "On the Determination of Regional Base and Regional Base Multipliers," Regional Science and Urban Economics, 22, 619-635.

Dahl, Christian M. 2002. "An Investigation of Tests for Linearity and the Accuracy of Likelihood Based Inference Using Random Fields," Econometrics Journal, 5, $263-284$

Dahl, Christian M. and Gloria González-Rivera. 2003. "Testing for Neglected Nonlinearity in Regression Models Based on the Theory of Random Fields," Journal of Econometrics, 114, 141-164.

Dahl, Christian M., Gloria González-Rivera and Yu Qin. 2005. "Statistical Inference and Prediction in Nonlinear Models Using Additive Random Fields," Working Paper, Department of Economics, Purdue University.

DeJong, David N. and Charles H. Whiteman. 1993. "Estimating Moving Average Parameters: Classical Pileups and Bayesian Posteriors," Journal of Business and Economic Statistics, 11, 311-317. 
Dickey David A. and Wayne A. Fuller. 1979. "Distribution of the Estimators For Autoregressive Time Series With a Unit Root," Journal of the American Statistical Association, 74, 427-431.

Diebold, Francis X. and Atsushi Inoue. 2001. "Long Memory and Regime Switching," Journal of Econometrics, 105, 131-159.

Dietzenbacher, Erik. 2005. "More On Multipliers," Journal of Regional Science, 46, $421-426$.

Dolado, Juan J., Jesus Gonzalo and Laura Mayoral. 2002. "A Fractional DickeyFuller Test for Unit Roots," Econometrica, 70, 1963-2006.

Dolado, Juan J., Tim Jenkinson and Simon Sosvilla-Rivero. 1990. "Cointegration and Unit Roots," Journal of Economic Surveys, 4, 249-273.

Doornik, Jurgen A. and Marius Ooms. 1999. "A Package for Estimating, Forecasting and Simulating ARFIMA Models: ARFIMA Package 1.0 for Ox," Discussion Paper, Nuffield College, University of Oxford.

Engle, Robert F. and Clive W. J. Granger. 1987. "Co-integration and Error Correction: Representation, Estimation and Testing," Econometrica, 55, 251-276.

Geweke, John F. and Susan Porter-Hudak. 1983. "The Estimation and Application of Long-Memory Time Series Models," Journal of Time Series Analysis, 4, 221237.

Hamilton, James D. 2001. "A Parametric Approach to Flexible Nonlinear Inference," Econometrica, 69, 537-573.

Hamilton, James D. 2005. "Comments on 'Investigating Nonlinearity'," Studies in Nonlinear Dynamics and Econometrics, 9, Article 3.

Hansen, Bruce E. 1996. "Inference When a Nuisance Parameter is Not Identified Under the Null Hypothesis," Econometrica, 64, 413-430.

Harrison, Michael J. and Derek Bond. 1992. "Testing and Estimation in Unstable Dynamic Models: A Case Study," The Economic and Social Review, 24, 25-49. 
Harrison, Michael J. and Edward J. O'Brien. 2007. "Testing for Nonlinearity: A Note on the Power of Random Field LM-Type Approaches," Trinity Economic Papers, forthcoming.

Kwiatkowski, Denis, Phillips, Peter C. B., Schmidt, Peter and Shin, Yongcheol 1992. "Testing the Null Hypothesis of Stationarity Against the Alternative of a Unit Root," Journal of Econometrics, 54, 159-178.

LeSage, James P. 1990. "Forecasting Metropolitan Employment Using an ExportBase Error Correction Model," Journal of Regional Science, 30, 307-323.

MacKinnon, James G. 1996. "Numerical Distribution Functions for Unit Root and Cointegration Tests," Journal of Applied Econometrics, 11, 601-618.

Maynard, Alex and Peter C. B. Phillips. 2001. "Rethinking an Old Empirical Puzzle: Econometric Evidence on the Forward Discount Anomaly," Journal of Applied Econometrics, 16, 671-708.

Ng, Serena and Pierre Perron. 2001. "Lag Length Selection and the Construction of Unit Root Tests with Good Size and Power," Econometrica, 69, 1519-1554.

Perron, Pierre. 1989. "The Great Crash, the Oil Price Shock and the Unit Root Hypothesis," Econometrica, 57, 1361-1401.

Perron, Pierre and Serena Ng. 1996. "Useful Modifications to Some Unit Root Tests with Dependent Errors and Their Local Asymptotic Properties," Review of Economic Studies, 63, 435-463.

Pfester, Ralph. 1976. "On Improving Export Base Studies," Regional Science Perspectives, 8, 104-116.

Robinson, Peter M. 1994. "Efficient Tests of Nonstationary Hypotheses," Journal of the American Statistical Association, 89, 1420-1437.

Robinson, Peter M. 1995. "Gaussian Semiparametric Estimation of Long Range Dependence," Annals of Statistics, 23, 1630-1661. 
Smith, Anthony A. Jr., Fallaw Sowell and Stanley E. Zin. 1997. "Fractional Integration with Drift: Estimation in Small Samples," Empirical Economics, 22, 103-116.

Sowell, Fallaw. 1992. "Maximum Likelihood Estimation of Stationary Univariate Fractionally Integrated Time Series Models," Journal of Econometrics, 53, 165188. 


\section{APPENDIX}

\section{TABLES}

Table 1: Basic $I(1) / I(0)$ Analysis

\begin{tabular}{cccc}
\hline Model SERIES & $\underset{(\text { Adob. }}{\mathrm{ADa}})$ & $\mathrm{KPSS}^{(b)}$ & $\mathrm{NP}^{(c)}$ \\
\hline $1959-1971$
\end{tabular}

Вотн

$\begin{array}{cccc}\text { Base } & -0.35 & \mathrm{~N} & \mathrm{~N} \\ & (0.55) & & \end{array}$

MOdel 1

$\begin{array}{llll}\text { Autonomous } & 2.43 & \mathrm{R} & \mathrm{N} \\ \text { Non-base } & (0.99) & & \\ & 0.80 & \mathrm{~N} & \mathrm{~N} \\ & (0.88) & & \end{array}$

MODEL 2

$\begin{array}{llll}\text { Autonomous } & 2.29 & \mathrm{R} & \mathrm{N} \\ \text { Non-base } & (0.99) & \mathrm{N} & \mathrm{N} \\ & 0.25 & & \\ & (0.75) & & \\ & 1978-1986 & & \end{array}$

Вотн

$\begin{array}{llll}\text { Base } & -1.50^{(*)} & \mathrm{R} & \mathrm{N} \\ (0.07) & & & \end{array}$

MOdel 1

$\begin{array}{lccc}\text { Autonomous } & -0.20 & \mathrm{~N} & \mathrm{~N} \\ \text { Non-base } & (0.61) & & \mathrm{N} \\ & -0.27 & & \mathrm{~N}\end{array}$

MODEL 2

\begin{tabular}{|c|c|c|}
\hline Autonomous & $\begin{array}{c}-2.06^{(*)} \\
(0.02)\end{array}$ & $\mathrm{R}$ \\
\hline Non-base & $\begin{array}{c}-0.12 \\
(0.63)\end{array}$ & $\mathrm{N}$ \\
\hline
\end{tabular}

a: Probabilities derived from MacKinnon (1996) unless otherwise noted.

b: $\mathrm{N} / \mathrm{R}=$ null of stationarity not rejected / rejected at 5 per cent level.

c: $\mathrm{N} / \mathrm{R}=$ null of unit root not rejected / rejected at 5 per cent level.

* Constant term included in test; probabilities from normal distribution. 
Table 2: Fractional Analysis

\begin{tabular}{lrrrr}
\hline Model & SERIES & EML & $\begin{array}{c}\text { NLS GPH } \\
\operatorname{FADF}^{(a)}\end{array}$ & GSP \\
& & \\
\hline & $1959-1971$
\end{tabular}

\section{Вотн}

MOdel 1

$\begin{array}{lllll}\text { Base } & 0.79 & 0.77 & 0.74 & 0.97 \\ & (1.13) & (1.13) & (0.18) & (0.16) \\ & -1.62 & -1.60 & -1.56 & -1.83\end{array}$

$\begin{array}{lcccc}\text { Autonomous } & 0.82 & 0.81 & 1.11 & 1.10 \\ & (0.13) & (0.12) & (0.18) & (0.16) \\ \text { Non-base } & 3.75 & 3.74 & . . & . . \\ & 0.62 & 0.64 & 0.81 & 0.70 \\ & (0.12) & (0.11) & (0.18) & (0.16) \\ & 1.38 & 1.39 & 1.44 & 1.43\end{array}$

Model 2

$\begin{array}{lcccc}\text { Autonomous } & 0.37 & 0.48 & 1.02 & 0.96 \\ & (0.13) & (0.13) & (0.18) & (0.16) \\ \text { Non-base } & 6.49 & 6.05 & . . & 4.15 \\ & 0.69 & 0.70 & 0.93 & 0.96 \\ & (1.12) & (1.11) & (0.18) & (0.16) \\ & 1.61 & 1.66 & 1.92 & 1.94 \\ & & & & \\ 1 & & & \end{array}$

Вотн

$\begin{array}{lllll}\text { Base } & 1.33 & 1.38 & 1.11 & 1.07 \\ & (0.13) & (0.15) & (0.23) & (0.18)\end{array}$

MOdel 1

$\begin{array}{lcccc}\text { Autonomous } & 1.30 & 1.20 & 0.95 & 0.92 \\ & (0.21) & (0.16) & (0.23) & (0.18) \\ \text { Non-base } & . . & . . & -1.16 & -1.14 \\ & 1.02 & 1.02 & 0.85 & 0.76 \\ & (0.15) & (0.15) & (0.23) & (0.18) \\ & . . & . . & 3.20 & 3.04\end{array}$

Model 2

$\begin{array}{lcccc}\text { Autonomous } & 1.18 & 1.09 & 0.78 & 0.92 \\ & (0.26) & (0.13) & (0.23) & (0.18) \\ \text { Non-base } & . . & . . & 3.11 & 3.00 \\ & 1.09 & 1.09 & 1.38 & 1.21 \\ & (0.16) & (0.17) & (0.23) & (0.18)\end{array}$

Note: standard deviations in parentheses.

a: FADF only applicable when $0<d<1$. 
Table 3: Level Models Results

Model Constant Base Autonomous $\operatorname{ADF}^{(a)} \quad \mathrm{NP}^{(b)} \quad \mathrm{KPSS}^{(c)}$

$$
1959-1971
$$

\begin{tabular}{ccccccc} 
Model 1 & 156556.30 & -0.16 & 0.06 & -1.80 & $\mathrm{~N}$ & $\mathrm{~N}$ \\
Model 2 & $(15609.80)$ & $(0.09)$ & $(0.03)$ & {$[0.07]$} & & \\
& $(27660.90)$ & -0.36 & 0.33 & -1.02 & $\mathrm{~N}$ & $\mathrm{~N}$ \\
& \multicolumn{7}{c}{$19.16)$} & $(0.07)$ & {$[0.27]$} & & \\
& \multicolumn{7}{c}{$1978-1986$}
\end{tabular}

$\begin{array}{lcccccc}\text { ModeL 1 } & 31922.80 & -0.16 & 0.72 & -2.17 & \mathrm{~N} & \mathrm{~N} \\ & (42535.60) & (0.03) & (0.20) & {[0.03]} & & \\ \text { Model 2 } & -13106.20 & 0.40 & 0.89 & -0.87 & \mathrm{~N} & \mathrm{~N} \\ & (55043.60) & (0.07) & (0.25) & {[0.34]} & & \end{array}$

Note: standard deviations in round brackets.

a: Probabilities derived from MacKinnon (1996) in square brackets.

b: $\mathrm{N}=$ Null of unit root not rejected at 5 per cent level.

c: $\mathrm{N}=$ Null of stationarity not rejected at 5 per cent level. 
Table 4: Non-linear Test Results

\begin{tabular}{|c|c|c|c|c|c|}
\hline MODEL & & $\lambda_{H}^{E}(\boldsymbol{g})$ & $\lambda_{O P}^{A}$ & $\lambda_{O P}^{E}(\boldsymbol{g})$ & $g_{O P}$ \\
\hline \multicolumn{6}{|c|}{$1959-1971$} \\
\hline MODEL 1 & $\begin{array}{l}\text { No Trend } \\
\text { Asymptotic } p \text { - value } \\
\text { Bootstrapped } p \text {-value } \\
(a)\end{array}$ & $\begin{array}{l}52.11 \\
(0.00) \\
(0.00)\end{array}$ & $\begin{array}{r}232.70 \\
(0.00) \\
(0.00)\end{array}$ & $\begin{array}{l}37.37 \\
(0.00) \\
(0.00)\end{array}$ & $\begin{array}{l}6.31 \\
(0.28) \\
(0.00)\end{array}$ \\
\hline MODEL 1 & $\begin{array}{l}\text { Trend } \\
\text { Asymptotic } p \text {-value } \\
\text { Bootstrapped } p \text {-value }^{(a)}\end{array}$ & $\begin{array}{l}67.73 \\
(0.00) \\
(0.00)\end{array}$ & $\begin{array}{c}302.44 \\
(0.00) \\
(0.00)\end{array}$ & $\begin{array}{l}50.49 \\
(0.00) \\
(0.00)\end{array}$ & $\begin{array}{l}17.29 \\
(0.04) \\
(0.00)\end{array}$ \\
\hline MODEL 2 & $\begin{array}{l}\text { No Trend } \\
\text { Asymptotic } p \text {-value } \\
\text { Bootstrapped } p \text {-value }{ }^{(a)}\end{array}$ & $\begin{array}{l}40.98 \\
(0.00) \\
(0.00)\end{array}$ & $\begin{array}{r}313.10 \\
(0.00) \\
(0.00)\end{array}$ & $\begin{array}{l}28.26 \\
(0.00) \\
(0.00)\end{array}$ & $\begin{array}{c}9.31 \\
(0.10) \\
(0.00)\end{array}$ \\
\hline MODEL 2 & $\begin{array}{l}\text { Trend } \\
\text { Asymptotic } p \text {-value } \\
\text { Bootstrapped } p \text {-value }{ }^{(a)}\end{array}$ & $\begin{array}{l}73.15 \\
(0.00) \\
(0.00)\end{array}$ & $\begin{array}{r}392.30 \\
(0.00) \\
(0.00)\end{array}$ & $\begin{array}{l}55.16 \\
(0.00) \\
(0.00)\end{array}$ & $\begin{array}{l}19.05 \\
(0.03) \\
(0.00)\end{array}$ \\
\hline \multicolumn{6}{|c|}{$1978-1986$} \\
\hline MODEL 1 & $\begin{array}{l}\text { No Trend } \\
\text { Asymptotic } p \text {-value } \\
\text { Bootstrapped } p \text {-value }^{(a)}\end{array}$ & $\begin{array}{l}3.85 \\
(0.05) \\
(0.04)\end{array}$ & $\begin{array}{l}38.19 \\
(0.00) \\
(0.01)\end{array}$ & $\begin{array}{l}0.08 \\
(0.78) \\
(0.91)\end{array}$ & $\begin{array}{c}3.39 \\
(0.64) \\
(0.00)\end{array}$ \\
\hline MODEL 1 & $\begin{array}{l}\text { Trend } \\
\text { Asymptotic } p \text {-value } \\
\text { Bootstrapped } p \text {-value }{ }^{(a)}\end{array}$ & $\begin{array}{l}8.78 \\
(0.00) \\
(0.01)\end{array}$ & $\begin{array}{c}145.64 \\
(0.00) \\
(0.00)\end{array}$ & $\begin{array}{l}1.22 \\
(0.27) \\
(0.68)\end{array}$ & $\begin{array}{c}200.09 \\
(0.00) \\
(0.00)\end{array}$ \\
\hline MODEL 2 & $\begin{array}{l}\text { No Trend } \\
\text { Asymptotic } p \text {-value } \\
\text { Bootstrapped } p \text {-value }{ }^{(a)}\end{array}$ & $\begin{array}{l}38.50 \\
(0.00) \\
(0.00)\end{array}$ & $\begin{array}{l}55.88 \\
(0.00) \\
(0.00)\end{array}$ & $\begin{array}{l}19.07 \\
(0.00) \\
(0.00)\end{array}$ & $\begin{array}{l}3.38 \\
(0.64) \\
(0.02)\end{array}$ \\
\hline MODEL 2 & $\begin{array}{l}\text { Trend } \\
\text { Asymptotic } p \text {-value } \\
\text { Bootstrapped } p \text {-value }{ }^{(a)}\end{array}$ & $\begin{array}{l}27.08 \\
(0.00) \\
(0.00)\end{array}$ & $\begin{array}{l}10.78 \\
(0.38) \\
(0.02)\end{array}$ & $\begin{array}{c}9.86 \\
(0.00) \\
(0.00)\end{array}$ & $\begin{array}{l}14.40 \\
(0.11) \\
(0.01)\end{array}$ \\
\hline
\end{tabular}

a: The bootstrapped $p$-values are based on 1,000 re-samplings. 
Table 5: Random Field Estimation

\begin{tabular}{|c|c|c|c|c|}
\hline & \multicolumn{2}{|c|}{$1959-1971$} & \multicolumn{2}{|c|}{$1978-86$} \\
\hline & MODEL 1 & MODEL 2 & Model 1 & MODEL 2 \\
\hline \multicolumn{5}{|c|}{ WithoutTrend } \\
\hline LINEAR TERM & & & & \\
\hline constant & $\underset{(17182.6)}{135532.2}$ & $\begin{array}{c}167966.1 \\
(33984.7)\end{array}$ & .. & $\begin{array}{c}-53488.7 \\
(64331.2)\end{array}$ \\
\hline base & $\begin{array}{c}-0.03 \\
(0.09)\end{array}$ & $\begin{array}{l}-0.05 \\
(0.16)\end{array}$ & .. & $\begin{array}{l}0.45 \\
(1.07)\end{array}$ \\
\hline autonomous & $\begin{array}{l}0.06 \\
(0.05)\end{array}$ & $\begin{array}{l}0.21 \\
(0.16)\end{array}$ & .. & $\begin{array}{l}1.07 \\
(0.29)\end{array}$ \\
\hline \multicolumn{5}{|c|}{ NON-LINEAR TERMS } \\
\hline$\sigma$ & $\begin{array}{c}1976.4 \\
(227.9)\end{array}$ & $\begin{array}{c}2523.4 \\
(377.5)\end{array}$ & .. & $\begin{array}{c}2133.7 \\
(642.0)\end{array}$ \\
\hline$\zeta$ & $\begin{array}{l}0.60 \\
(0.19)\end{array}$ & $\begin{array}{l}1.49 \\
(0.48)\end{array}$ & .. & $\begin{array}{l}0.50 \\
(0.43)\end{array}$ \\
\hline base & $\begin{array}{c}0.00 \\
(0.000025)\end{array}$ & $\begin{array}{c}0.000032 \\
(0.000058)\end{array}$ & .. & $\begin{array}{l}0.00020 \\
(0.000081)\end{array}$ \\
\hline autonomous & $\begin{array}{c}-0.00011 \\
(0.000026)\end{array}$ & $\begin{array}{c}0.00012 \\
(0.000012)\end{array}$ & .. & $\begin{array}{l}0.00030 \\
(0.00021)\end{array}$ \\
\hline \multicolumn{5}{|c|}{ With Trend } \\
\hline \multicolumn{5}{|c|}{ LINEAR TERMS } \\
\hline constant & $\begin{array}{c}134834.8 \\
(28558.5)\end{array}$ & $\begin{array}{c}302099.9 \\
(31834.3)\end{array}$ & $\begin{array}{l}45367.1 \\
(40221.6)\end{array}$ &.. \\
\hline base & $\begin{array}{c}-0.01 \\
(0.10)\end{array}$ & $\begin{array}{c}-0.20 \\
(0.14)\end{array}$ & $\begin{array}{l}0.35 \\
(0.21)\end{array}$ & .. \\
\hline autonomous & $\begin{array}{l}0.03 \\
(0.16)\end{array}$ & $\begin{array}{c}-1.02 \\
(0.25)\end{array}$ & $\begin{array}{l}0.29 \\
(0.18)\end{array}$ & .. \\
\hline$t$ & $\begin{array}{l}68.45 \\
(137.1)\end{array}$ & $\begin{array}{l}892.8 \\
(181.5)\end{array}$ & $\begin{array}{l}710.1 \\
(274.9)\end{array}$ & .. \\
\hline \multicolumn{5}{|c|}{ NON-LINEAR TERMS } \\
\hline$\sigma$ & $\begin{array}{c}1307.9 \\
(235.9)\end{array}$ & $\begin{array}{l}933.3 \\
(657.2)\end{array}$ & $\begin{array}{l}669.8 \\
(380.9)\end{array}$ &.. \\
\hline$\zeta$ & $\begin{array}{l}1.81 \\
(0.77)\end{array}$ & $\begin{array}{l}3.66 \\
(3.17)\end{array}$ & $\begin{array}{l}5.29 \\
(4.28)\end{array}$ & .. \\
\hline base & $\begin{array}{c}0.00 \\
(0.00002)\end{array}$ & $\begin{array}{c}0.00 \\
(0.00004)\end{array}$ & $\begin{array}{c}-0.000002 \\
(0.0001)\end{array}$ & .. \\
\hline autonomous & $\begin{array}{c}0.00 \\
(0.00004)\end{array}$ & $\begin{array}{c}0.00008 \\
(0.0001)\end{array}$ & $\begin{array}{c}0.00 \\
(0.00002)\end{array}$ & .. \\
\hline$t$ & $\begin{array}{l}0.11 \\
(0.02)\end{array}$ & $\begin{array}{l}0.26 \\
(0.03)\end{array}$ & $\begin{array}{c}0.08 \\
(0.008)\end{array}$ & .. \\
\hline
\end{tabular}

Note: standard deviations in parentheses. 